EESTI NSV TEADUSTE AKADEEMIA TOIMETISED. XIV KÖIDE

FOOSIKA-MATEMAATIKA- JA TEHNIKATEADUSTE SEERIA. 1965, NR. 1

ИЗВЕСТИЯ АҚАДЕМИИ НАУК ЭСТОНСКОН ССР. ТОМ ХІV

СЕРИЯ ФИЗИКО-МАТЕМАТИЧЕСКИХ И ТЕХНИЧЕСКИХ НАУК. 1965, № 1

Н. КЛЕСМЕНТ, О. ЭИЗЕН

\title{
ИЗУЧЕНИЕ СТРУКТУРЫ ФЕНОЛОВ ПУТЕМ ДЕГИДРОКСИЛИРОВАНИЯ ИХ В АРОМАТИЧЕСКИЕ УГЛЕВОДОРОДЫ
}

В последнее время для анализа фенолов начали применять газо-жидкостную хроматографию [1-3]. Широкое внедрение этого метода усложняется тем, что фенолы, как высокополярные вещества, сильно адсорбируются на общеприменяемых носителях жндкой фазы. Кроме того, отсутствие соответствующих индивидуальных соединенин̆ затрудняет применение этого метода для изучения высокомолекулярных фенолов. В связи со сказанным газо-жидкостная хроматография применялась до сих пор главным образом при изучении состава относительно низкокипящих фенолов.

Целью настоящей работы было упростить анализ фенолов, применив гидрирование нх в соответствующие углеводороды, разделение которых не представляет трудностей. Такой путь, хотя и не дает возможности определить расположение гидроксильной группы, позволяет узнать структуру углеводородного скелета.

Фенолы можно гидрировать в ароматические углеводороды или производные циклогексана. Первое выгоднее, так как полиалкилированные производные циклогексана присутствуют в виде цис-транс-изомеров, количество которых больше, чем у соответствующих ароматических соединений и, следовательно, анализ сложнее.

На промышленных катализаторах (никель, окись и сульфид молибдена [4]) гидрирование фенолов в ароматические углеводороды сопровождается деструктивными процессами. Слабее эти процессы протекают на Pt- и Pd-катализаторах, которые используются в промышленности и лаборатории для дегидрирования нафтенов [5-7], для определения структуры различных кислородных, сернистых, азотистых и хлористых соединений путем гидрирования в углеводороды [8, 9]. Эти катализаторы были использованы и в настоящей работе.

По данным литературы, палладиевые катализаторы более устойчивы к различным ядам $\left[{ }^{8,9}\right]$, чем платиновые; кроме того гидрогенолиз пентаметиленового кольца происходит на Pd-катализаторе в меньшей степени, чем на платине $\left[{ }^{10}\right]$. Подходящим инертным носителем катализатора оказался диатомит, используемый как носитель СЖФ в газовой хроматографии. Для приготовления палладиевого катализатора носитель $(0,3-0,5$ мм) пропитывался водным раствором хлористого палладия и восстанавливался в токе водорода при $350-400^{\circ} \mathrm{C}$. В нижеописываемых опытах использовали катализатор, содержащий $5 \%$ палладия.

Для анализа катализата и как вспомогательный прибор при гидрировании применялся двухколоночный хроматограф УХ-I, первая колонка которого была заменена реактором гидрирования. Реакторами служили медные трубки ( $6 / 4$ и $8 / 6$ мм), которые для обогрева помещались в трубчатую печь. Количество катализатора в реакторах было 2, 8 и 
20 мл. Последовательно с реактором были соединены хроматографическая колонка и ловушка, охлаждаемая твердой углекислотой для конденсации катализата. С помощью переключателя ток водорода мог быть направлен из реактора по мере необходимости то в колонку, то в ловушку. Так как фенолы при гидрировании заметно адсорбируются на катализаторе, необходима промежуточная конденсация катализата до хроматографирования.

При гидрировании фенолов образуется вода, мешающая при хроматографическом анализе. Для удаления воды перед ловушкой был поставлен патрон с карбидом кальция.

Хроматографической колонкой служила медная трубка длиной 3,2 , Ø 6/4 мм, СЖФ в колонке - полигликоль 4000, $20 \%$ от веса носителя - диатомита. Гидрируемые фенолы $(20-30$ мкл) растворяли в смеси $н$-гексана и серного эфира и доводили объем до 50-100 мкл.

С помощью микрошприца раствор фенолов вводился в течение 35 мин в ток водорода, проходящий через микрореактор и конденсационную систему. Скорость подачи водорода составляла при этом 30 мл/мин. Так как водород одновременно проходил детекторные ячейки хроматографа, показания регистрирующего прибора позволяли следить за процессом гидрогенизации. После выхода катализата, что в случае нафтолов продолжалось до 10 мин, систему промывали 50 мкл $н$-гексана. Затем ток водорода переключали на хроматографическую колонку, брали микрошприцем определенное количество катализата и производили его анализ.

Выяснилось, что дегидроксилирование фенолов идет значительно медленнее, чем дегидрогенизация нафтенов в тех же условиях. Для последнего процесса достаточно было 2 мл катализатора, в то время как для дегидроксилирования алкилфенолов требовалось 6 мл, а в случае нафтолов 20 мл катализатора.

Активность катализатора после каждого опыта проверяли по дегидрогенизации циклогексана в бензоле. Выходы бензола на свежем катализаторе в зависимости от температуры показаны на рис. 1. Активность катализатора значительно падала при дегидроксилировании нафтолов, гидроксидифенилов и в меньшей степени - инданолов. Алкилфенолы и простые дифенолы вредного действия не оказывали.

В случае дезактивации катализатор регенерировался в токе воздуха при $350^{\circ}$, что полностью восстанавливало его первоначальные свойства.

При дегидроксилировании фенолов состав катализата в основном зависит от температуры реактора. При низких температурах часть ароматических соединений гидрируется в производные циклогексана, при высоких температурах проходят нежелательные процессы дезалкилирования. О влиянии температуры реактора свидетельствуют результаты гидрирования технического трикрезола, изображенные на рис. 2. Трикрезол содержал $14,8 \%$ фенола, 58,5\% крезолов, 8,4\% этилфенолов, $17,5 \%$ ксиленолов и $0,8 \%$ метилэтилфенолов. Как видно из рис. 2, при температурах ниже $300^{\circ}$ образуются значительные количества производных циклогексана, которые при хроматографировании опережают ароматические соединения. При температуре $325^{\circ}$ и выше их количество незначительно. Лучше других соединений гидрируется бензол, но и он при $330^{\circ}$ гидрируется в циклогексан не больше, чем на $15 \%$ (см. рис. 1). Указанная температура достаточна для достижения равновесия на катализаторе.

При определении высшего температурного предела дегидроксилирования необходимо учитывать процессы дезалкилирования. Алкил- 

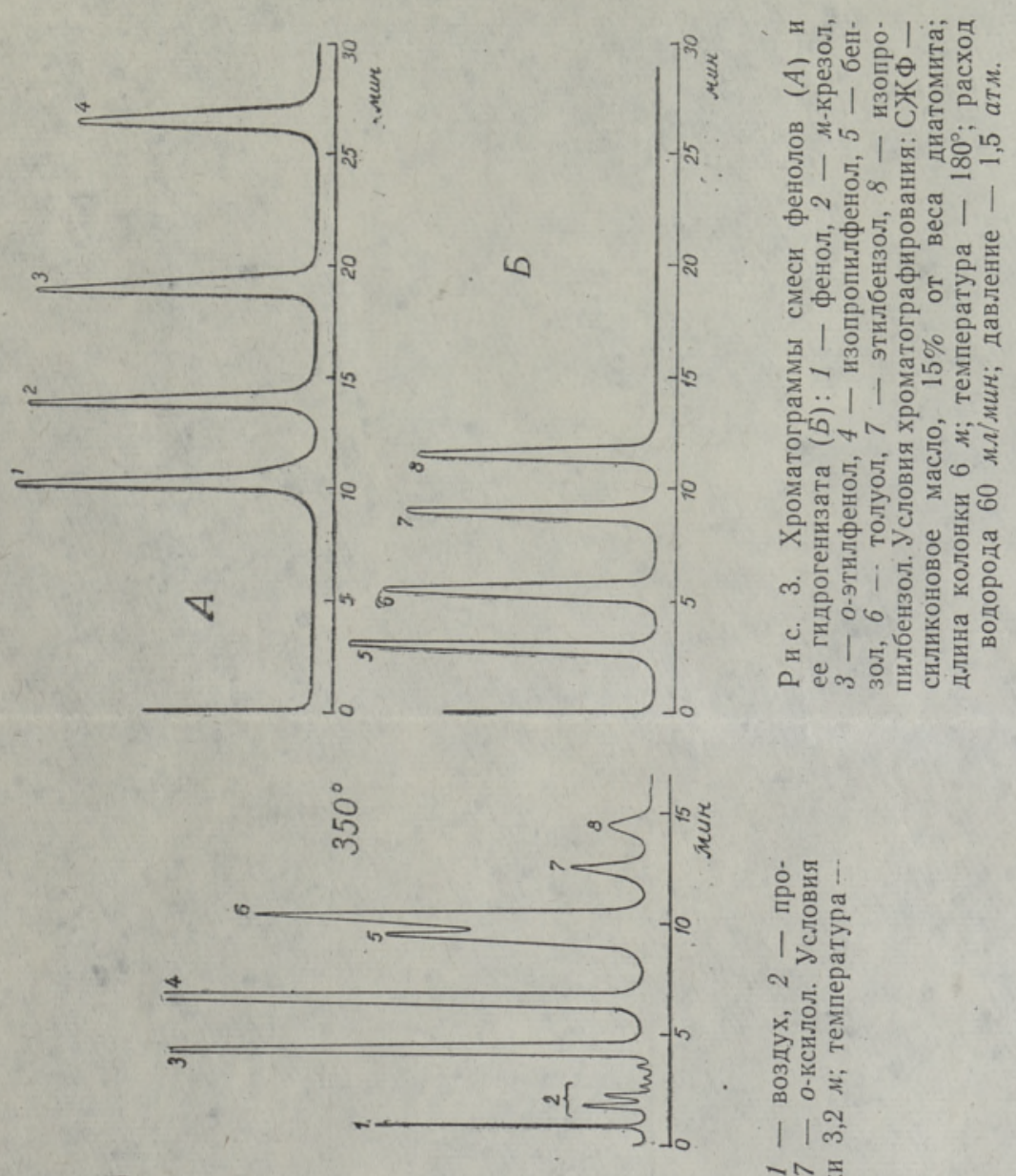

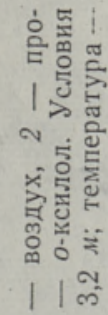

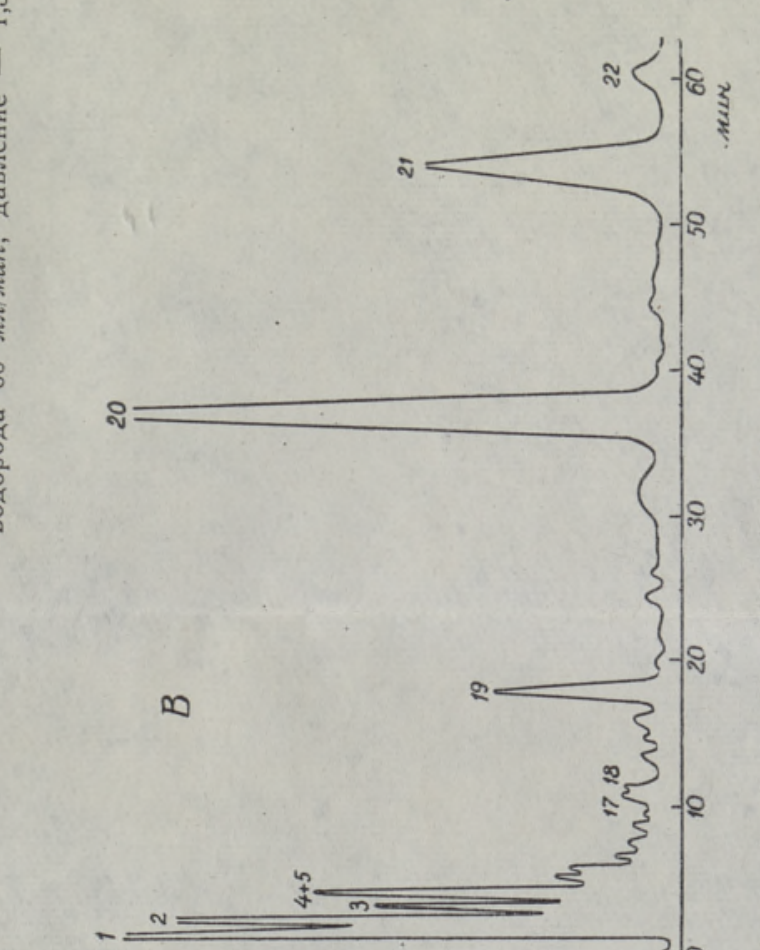

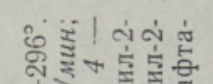

12

땡ำ $2=1$

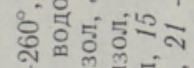

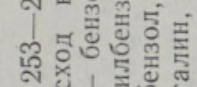

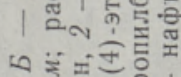

은.

ลิ่

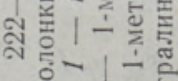

药|

$\checkmark$ 政

둠윰

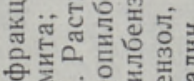

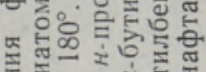

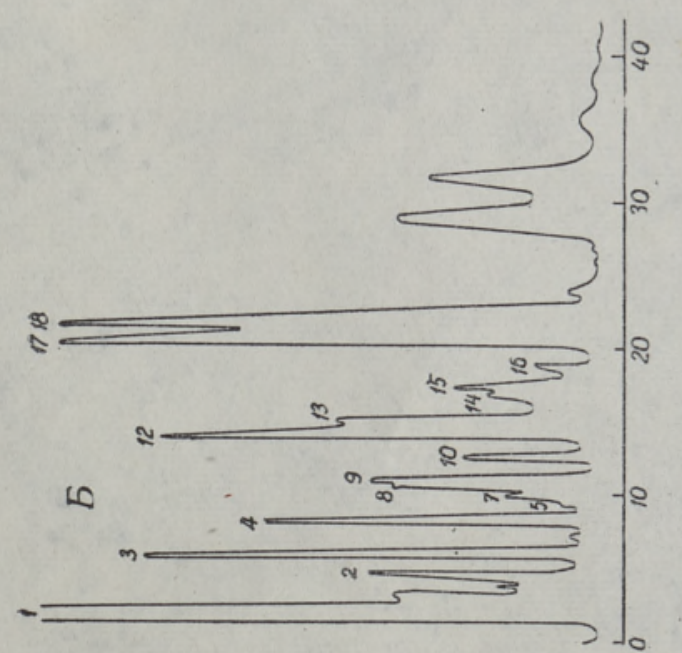

政 |

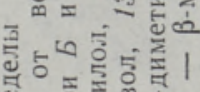

울

동

ํํำ

焉|

ए人

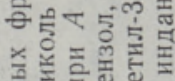

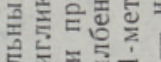

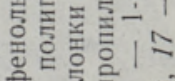

|

क⿺辶一兀

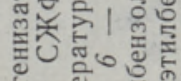

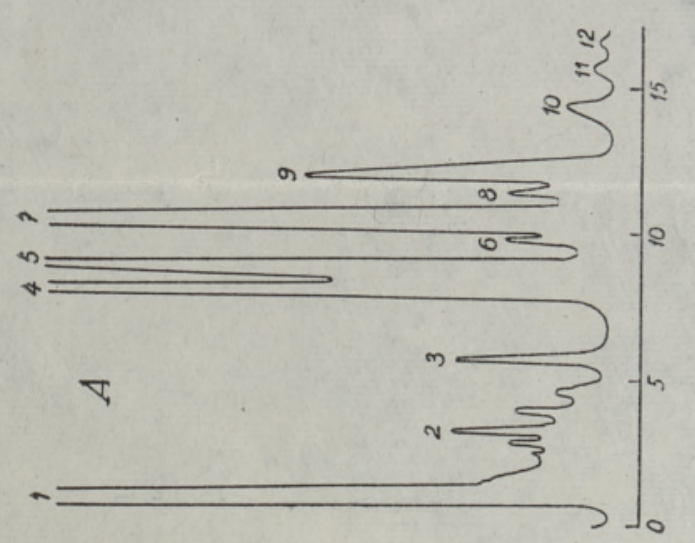

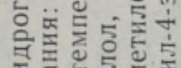

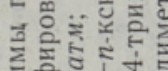

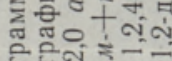

잉 11

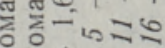

хे

เ

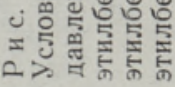

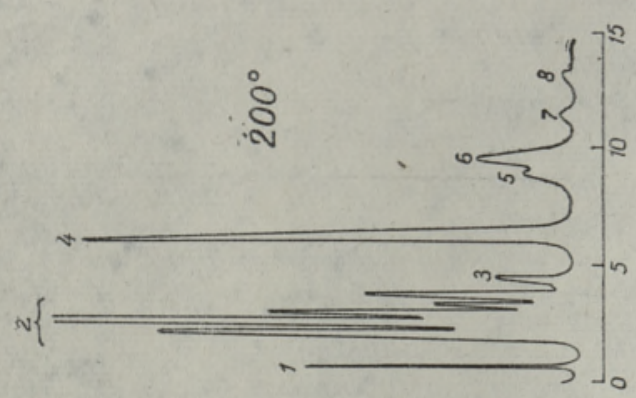

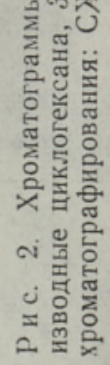
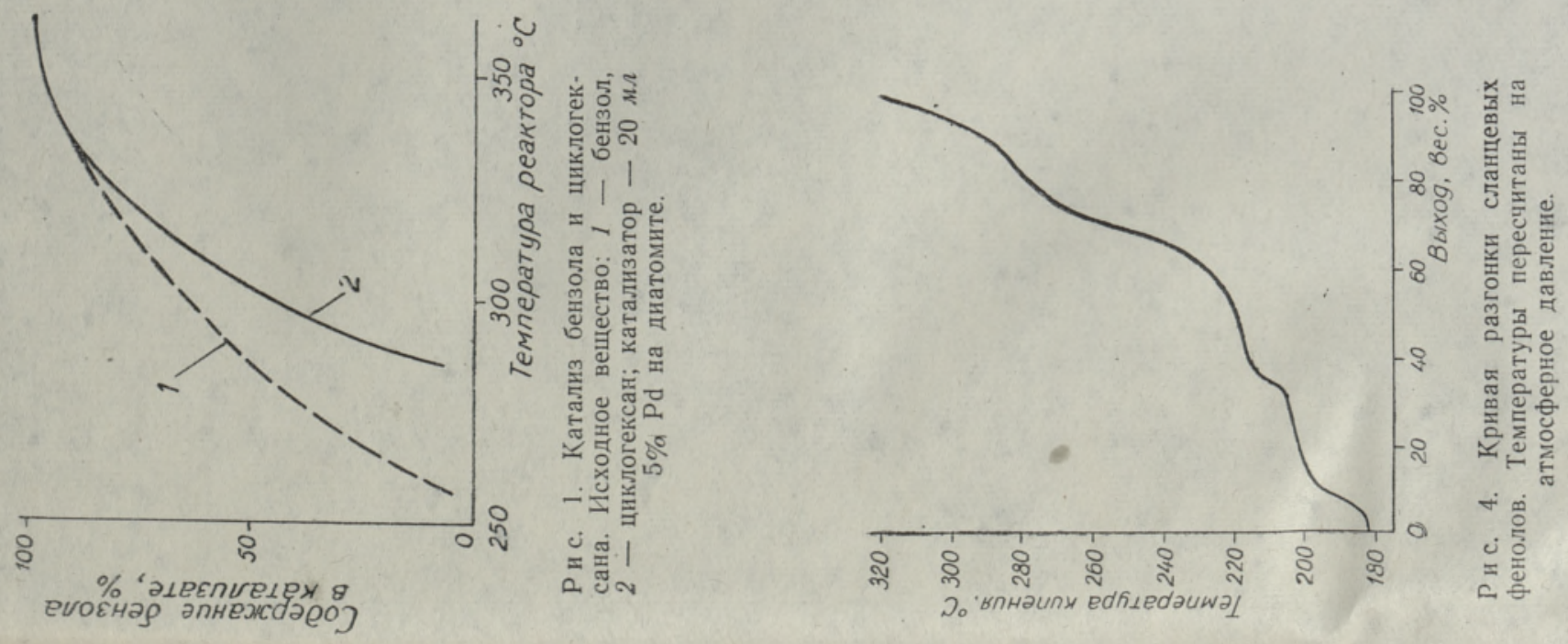

ароматические соединения на катализаторе устойчивы, но гидроксильная группа в молекуле фенола ослабляет связь с алкильными группамн. Особенно легко расщепляются $n$-алкильные и третичные группы [8].

Для выяснения стабильности разных структур фенолов в условиях дегидроксилирования, производили опыты со следующими фенолами: м-крезол, 3,4,5-триметилфенол, $o$-изопропилфенол, тимол, $n$-третичный бутилфенол, 5-инданол, $n$-гидроксидифенил, o-метоксифенол и др.

Опыты с этими фенолами при разных температурах показали, что метильные и этильные группы в условиях дегидроксилирования устойчивы до $360^{\circ}$. Значительно менее стабнльными оказались фенолы со сложным строением. n-Третичный бутилфенол дезалкилировался при $350^{\circ}$ почти полностью, расщепление прекращалось при температуре ниже $250^{\circ}$. При $350^{\circ}$ изопропильная группа тимола дезалкилировалась на $10 \%$ и $n$-гидроксидифенил разлагался до бензола на $31 \%$. Интересно отметить, что циклопентановое кольцо 5-инданола при дегидроксилировании на палладии подвергалось гидрогенолизу незначительно. В опытах с инданом на платиновом катализаторе при $350^{\circ}$ он расщеплялся до $60 \%$. В условиях дегидроксилирования в боковых цепях фенолов отделялся также нейтральный кислород (эфирный или карбонильный).

Проведенные опыты показали, что более разветвленные алкильные группы фенолов в условиях дегидроксилирования нестабильны. Дегидрокеилирование фенолов рекомендуется проводить при температурах $325-340^{\circ}$.

На рис. 3 изображены хроматограммы искусственной смеси фенолов и продуктов ее дегидроксилирования в вышеописанных условиях при $335^{\circ}$. В отличие от других анализов хроматографирование произведено на колонке с неполярной СЖФ - силиконовым маслом. Результаты показывают, что при дегидроксилировании фенолы исчезают, а вместо них образуются соответственные ароматические углеводороды.

Разработанную методику использовали для анализа фенолов, получаемых при газификации эстонского горючего сланца в камерных печах при $800^{\circ}$. В вакууме от исходной смеси отгоняли фракцию, кипящую при температуре до $370^{\circ}$. Фенолы выделяли $20 \%$-ной щелочью, из фенолята серным эфиром экстрагировали нейтральные масла, и фенолят разлагался кислотой. Высушенные фенолы ректифицировали на вакуумной колонке с разделительной способностью 35 теоретических тарелок. Объектом исследования служили 38 фракций, кипящих при температуре до $300^{\circ}$. Их выход составлял $41,7 \%$ от исходных фенолов и $2,8 \%$ от исходной смолы. Кривая разгонки фенолов изображена на рис. 4.

Фракции гидрировали и хроматографировали вышеописанным методом. Хроматограммы некоторых фракций изображены на рис. 5.

Пики на хроматограммах идентифицировали путем сравнения с объемами удерживания соответствующих индивидуальных углеводородов.

С повышением температуры кипения содержание простейших алкилбензолов в катализате сначала повышается, потом падает, после чего в высококипящих фракциях снова немного повышается. Первому подъему соответствуют одноатомные фенолы, второму - двухатомные.

Окончательный баланс анализа - индивидуальные ароматические соединения, идентифицированные в катализате, и их содержание в анализируемой части приведены в таблице.

Всего было определено 93\% углеводородной структуры фенолов.

Исследованные фенолы имеют высокое содержание этильной группы - этилфенола такое же количество, как всех ксиленолов вместе 
Ароматические углеводороды в дегидроксилате сланцевых фенолов

\begin{tabular}{|c|c|c|c|c|}
\hline \multirow[t]{2}{*}{ Названия углеводородов } & \multicolumn{2}{|c|}{$\begin{array}{l}\text { Содержание } \\
\text { структур в } \\
\text { фенолах, \% }\end{array}$} & \multicolumn{2}{|c|}{$\begin{array}{c}\text { Относитель- } \\
\text { ные объемы } \\
\text { удержива- } \\
\text { ния при тем- } \\
\text { пературе * }\end{array}$} \\
\hline & $\begin{array}{c}\text { одно- } \\
\text { атомных }\end{array}$ & $\begin{array}{c}\text { двух- } \\
\text { атомных }\end{array}$ & $150^{\circ}$ & $180^{\circ}$ \\
\hline 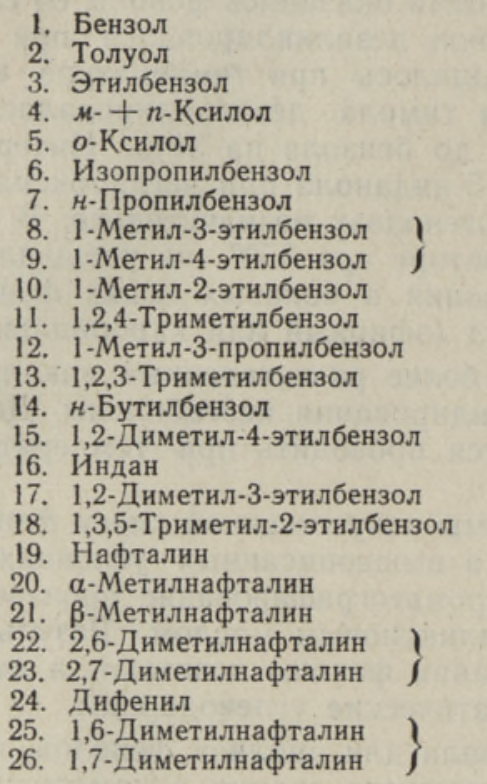 & $\begin{array}{r}8,1 \\
25,6 \\
9,5 \\
7,1 \\
3,5 \\
0,2 \\
0,7 \\
6,8 \\
1,7 \\
1,0 \\
1,1 \\
1,4 \\
0,4 \\
0,1 \\
1,2 \\
1,0 \\
0,3 \\
9,5 \\
4,2 \\
1,2 \\
0,2 \\
0,2 \\
0,3\end{array}$ & $\begin{array}{l}2,6 \\
1,8 \\
0,7 \\
0,5 \\
0,2 \\
\overline{0,7} \\
0.3 \\
0,5 \\
\overline{-} \\
\overline{0,4} \\
\overline{-} \\
\overline{-} \\
\overline{-} \\
\overline{-} \\
- \\
-\end{array}$ & $\begin{array}{c}100 \\
157 \\
233 \\
242 \\
307 \\
280 \\
381 \\
356 \\
424 \\
467 \\
498 \\
605 \\
524 \\
664 \\
733 \\
808 \\
1121 \\
- \\
- \\
- \\
- \\
- \\
-\end{array}$ & $\begin{array}{l}100 \\
151 \\
212 \\
222 \\
278 \\
269 \\
316 \\
346 \\
373 \\
404 \\
423 \\
515 \\
441 \\
552 \\
616 \\
664 \\
865 \\
100 \\
147 \\
166 \\
201 \\
214 \\
246\end{array}$ \\
\hline $\mathrm{Bcero}$ & 85,3 & 7,7 & & \\
\hline
\end{tabular}

* Относительные объемы удерживания при хроматографическом анализе рассчитаны для производных бензола по бензолу (бензол $=100$ ) и для пронзводных нафталина по нафталину (нафталин $=100)$.

взятых, метилэтилфенолов в несколько раз больше, чем триметилфенолов. По данным литературы, в буроугольной смоле также много этилфенолов $\left[{ }^{9}\right]$, но в каменноугольной смоле их мало $\left[{ }^{10}\right]$. Интересно отметить, что среди исследованных фракций не были обнаружены мезитиленовые структуры.

\section{Выводы}

1. Разработан микрореакторно-газохроматографический метод дегидроксилирования фенолов в соответствующие ароматические углеводороды.

2. В условиях дегидроксилирования частично дезалкилируются разветвленные алкильные группы фенолов, нормальные боковые цепи являются устойчивыми.

3. Разработанный метод применен для анализа сланцевых фенолов. 


\section{Л И Т Е Р А Т У Р А}

1. S o k o 1 L., Collection Czech. Chem. Commun., 24, 437 (1959).

2. Porcaro P. J., Johnston V. D., Anal. Chem., 34, No. 9, 1071 (1962).

3. K u s ý V., Gaschromatographie 1961, 3. Symp. G.-Chrom., Berlin, 1962, S. 321.

4. Ш уйкин Н. И., Э р и в а нска я Л. А., Успехн химни, 29, № 5,648 (1960).

5. Л андсберг Г. С., К азан ский Б. А. и др., Определение индивидуального состава бензинов прямой гонки комбинированным методом. Институт органической химни им. Н. Д. Зелннского. Изд. АН СССР, М., 1959, стр. 77.

6. K e u 1 e m a n s A. J. M., V o g e H. H., J. Phys. Chem., 63, No. 4, 476 (1959).

7. R ow a n R., Anal. Chem., 33, No. 6, 658 (1961).

8. Thomp son C. J., Colem an H. J., Hopkins R. L., W a r d C. C., R a 11 H. T., Anal. Chem., 32, No. 13, 1672 (1960).

9. Thompson C. J., Colem a n H. J., W a rd C. C., Ra11 H. T. Anal. Chem., 32, No. 4,424 (1960); 34, No. 1, 151 (1962); 34, No. 1, 154 (1962).

10. К а з а н ски й Б. А., Успехи хнмин, 17, вып. 6, 641 (1948).

11. Дирихс А., Кубичка Р., Фенолы и основания из углей, Гостоптехиздат, M., 1958, стр. 340 .

12. Preis s S., J. prakt. Chem., 1, 157 (1955).

13. J äg e r A., K a t t w i n ke l G., Brennstoff-Chemie, 31, 65 (1950).
Ннститут химии
Академии наук Эстонской ССР
Поступила в редакцию
$18 / \mathrm{IV}$
1964

\section{KLESMENT, O. EISEN}

\section{FENOOLIDE STRUKTUURI MAXARAMINE AROMAATSETEKS SUSIVESINIKEKS DEHODROKSOULIMISE TEEL}

Fenoolid dehüdroksüüliti Pd-katalüsaatoril mikroreaktoris $325-340^{\circ} \mathrm{C}$ juures (katalüsaadi koosseis määrati gaasikromatograafiliselt). Katalüüsil dehüdroksüüluvad alküülİenoolid kergesti, mitmetuumalised fenoolid teataval määral mürgitavad katalüsaatorit. Kasutatud tingimustes fenoolide tugevasti hargnenud kõrvalahelad osaliselt dealküüluvad. Väljatöötatud meetodiga uuriti kamberahju fenoolide koosseisu.

\section{KLESMENT, O. EISEN}

\section{STRUKTURBESTIMMUNG DER PHENOLE DURCH HYDRIERUNG ZU AROMATISCHEN KOHLENWASSERSTOFFEN}

Die Phenole wurden in einem Mikroreaktor mit Pd-Katalysator bei 325-340 $\mathrm{C}$ dehydroxyliert; die Zusammensetzung der aromatischen Kohlenwasserstoffe wurde gaschromatographisch bestimmt. Bei der Katalyse werden die Hydroxylgruppen der Alkylphenole leicht entfernt; die mehrkernigen Phenole vergiften den Katalysator einigermassen. Unter diesen Umständen werden starkverzweigte Alkylphenole teilweise entalkyliert. Diese Methode wurde zur Untersuchung der Phenole aus einem Hochtemperatur-Schieferteer benutzt. 